\title{
Forma e ethos do trabalho: ensaio sobre a reformulação de uma ideologia
}

\author{
Maurilio Lima Botelho \\ Universidade Federal Rural do Rio de Janeiro (UFRRJ)
}

Forma e ethos do trabalho: ensaio sobre a reformulação de uma ideologia

Resumo: Este ensaio explora as metamorfoses na chamada ideologia do trabalho, desde o ethos protestante do capitalismo clássico, passando pelo hedonismo da sociedade de consumo, até a atual reformulação dessa ideologia nos marcos de uma sociedade em crise. Enfatiza-se que as modificações ocorrem tanto na forma quanto no conteúdo desta ideologia, o que significa refletir sobre a sua relação com a efetividade social.

Palavras-chave: capitalismo, sociedade de consumo, crise do trabalho, trabalho abstrato.

\section{Form and Ethos of Labor: Essay on the Reformulation of an Ideology}

Abstract: This essay explores the changes in the so-called ideology of labor, from the classic Protestant work ethic, passing through the hedonism of consumer society to the current reformulation of this ideology in a society in crisis. It emphasizes that the modifications occur both in the form and content of this ideology, which stimulates an analysis of its relationship with social reality.

Key words: capitalism, consumer society, crisis of labor, abstract work. 
A emergência do consumo em massa no pós-guerra nos EUA e em alguns países da Europa Ocidental é um resultado não apenas da ampliação gigantesca da produtividade do trabalho, mas também da constituição de sociedades do "bem-estar social". Os novos métodos de organização produtiva (taylorismofordismo), generalizados com a estabilidade políticaeconômica, associam-se ao amplo conjunto de direitos sociais e trabalhistas inaugurados pela combinação de social-democracia e keynesianismo. Verifica-se, então, a classe trabalhadora participando das "benesses" do mercado e da própria vida política nacional. As massas, que passam parte significativa de seu dia no ambiente de trabalho, podem agora desfrutar, no "tempo livre", dos ganhos diretos dos salários ou dos mecanismos sociais do chamado salário indireto, que expandem de forma inédita a "esfera da reprodução operária". Para a teoria política, econômica e social, essa mudança representa uma abertura de novas questões e exige imediatamente uma revisão dos postulados clássicos, principalmente àqueles relativos ao ascetismo do trabalho, que repercute de modo imediato no problema do posicionamento político do trabalhador frente à socialização capitalista.

O problema que surge de modo muito nítido no pós-guerra - mas já anunciado pela Era do Rádio, pela indústria cinematográfica ou pela sociedade do automóvel de 1920-1930 nos EUA - é a validade de tratar o "espírito do capitalismo" nos termos ainda da ascese intramundana protestante. Relacionado a essa problematização - seja a priori ou como o seu efeito - surge a discussão sobre a "integração" operária, isto é, a antiga visualização do proletário como de algum modo alheio à sociedade de mercado não parece mais ter respaldo nos "fatos".

Sem querermos retomar essa discussão de um ponto de vista estritamente sociológico - o que nos levaria a tematizar a autonomia das esferas de valor weberiana e, portanto, a pretensa dissociação entre valores estéticos e valores racionais -, vamos refletir aqui sobre os caminhos tomados pela "ideologia do trabalho" ao longo desse processo de emergência de uma sociedade de consumo e o seu significado e sua validade hoje. No cerne de toda essa reflexão está dado não apenas o conteúdo da ideologia do trabalho, mas a própria forma da ideologia, que caracteriza o modo como a ideologia se envolve com os seus objetos sociais, o nexo entre ideologia e efetividade social.

\section{O ethos clássico caduca}

O filósofo Marcuse (1998) apontou, numa reflexão crítica de 1964 sobre a obra de Weber, que o ethos do trabalho que havia caracterizado o capita- lismo em seu período clássico já não era mais visível no pós-guerra. Embora de algum modo persista o "sacrifício" na sociedade burguesa - principalmente como submissão metódica e voluntária ao ambiente de trabalho extremamente racionalizado -, o "ascetismo" foi superado como comportamento determinante e como marca do "espírito do capitalismo". A "sociedade afluente", produzida pelo capitalismo desenvolvido, não apenas permitia como estimulava de modo racional, planejadamente, o consumo em grande escala, mesmo que isso tivesse uma lógica destrutiva por trás ${ }^{1}$.

Se Weber (2001, p. 130) havia anunciado que o "puritano quis trabalhar no âmbito da vocação; e todos fomos forçados a segui-lo", mesmo que essa generalização de uma racionalidade baseada no cálculo e na eficiência continuasse vigente, o que caracterizava o capitalismo do pós-guerra, para Marcuse, era exatamente a universalidade de um modelo de administração calcado na "razão técnica", capaz, inclusive, de transformar o consumo em um processo de catexização libidinal ${ }^{2}$. A tese central de $A$ ética protestante e o espirito do capitalismo era colocada em xeque: na época da "sociedade de consumo" uma conduta regida pela frugalidade havia caducado e o "consumo de mercadorias supérfluas", no mínimo, entrava em contradição com a lógica do ascetismo intramundano (MARCUSE, 1998, p. 118).

Com efeito, no período clássico e de afirmação do capitalismo ou na construção do socialismo real - cujo empenho em recuperar o atraso econômico-social fazia uso dos mesmos métodos primitivos de acumulação, modificados às condições históricas e geográficas específicas - a ideologia do trabalho havia impulsionado as massas a contribuírem para o acúmulo da "homogênea gelatina de trabalho" (MARX, 1985, p. 52), necessária para o libertar das forças produtivas. O discurso ideológico convencia os indivíduos da nobreza pressuposta no sofrimento do longo dia de trabalho, justificando o esforço recompensado por Deus (no caso das seitas protestantes) ou pela História, através da construção da Grande Pátria Socialista. Se não convenciam os grandes ideais, no mínimo se reconhecia que no envolvimento com a matéria, com os instrumentos de trabalho, processar-se-ia a formação da subjetividade (educação pelo trabalho, tema comum tanto à pedagogia liberal quanto à pedagogia do trabalho soviética). $\mathrm{O}$ ascetismo e a metódica virtuose na fábrica e no campo serviam de contribuição social para a autoformação, através da renúncia e do controle dos desejos, um "enobrecimento". Os "banhos frios" calvinistas e o "trabalho forma" hegeliano-marxista eram expressões desse ethos amplo que tentava dar conta dos resultados subjetivos do trabalho, processo este que não apenas contribuía objetivamente para o "enriquecimento geral" (a "riqueza das nações") quanto constituía individualidades próprias a uma socieda- 
de de sujeitos autorregulados (o "processo civilizador" de Norbert Elias, cujas facetas mais sombrias foram levantadas por Michel Foucault). A universalidade desse processo, atravessando fronteiras nacionais e de classe, foi ressaltada inúmeras vezes:

\begin{abstract}
Constitui uma das peculiaridades da sociedade ocidental que, no curso de seu desenvolvimento, tenha-se reduzido muito esse contraste entre a situação e o código de conduta dos estratos mais altos e mais baixos. As características das classes baixas difundem-se por todas as outras. Temos um sintoma disso no fato de que a sociedade ocidental como um todo gradualmente se tornou uma sociedade em que se espera que todas as pessoas capazes ganhem a vida através de um tipo altamente regulado de trabalho. Antes, o trabalho era uma característica das classes mais baixas, e, ao mesmo tempo, o que costuma ser peculiar às classes superiores também se difunde pela sociedade como um todo. A conversão de restrições sociais impostas 'de fora' em autorrestrições, numa autorregulação individual que se torna um hábito ou um automatismo no tocante às paixões e sentimentos - possivelmente apenas para pessoas normalmente protegidas da ameaça física, externa, da espada ou da fome - também está ocorrendo entre as grandes massas no Ocidente (ELIAS, 1993, p. 211).
\end{abstract}

A ideologia do trabalho, em suas variações protestante e, posteriormente, marxista, apresentava-se no sentido clássico como "falsa consciência", indicando um conjunto de representações que contrapunham um ideal ornamentado a uma realidade empírica que era marcada pela exploração, brutalidade, esforço descomunal e envilecimento. A consciência falsa se opunha a um mundo, cuja verdade objetiva ela mesma pretendia legitimar. Longe, portanto, de mera falsidade abstrata, tratava-se de uma idealização que, ao mesmo tempo em que executava sua função positiva e legitimadora, tentando conciliar os indivíduos a um mundo fraturado, exprimia esta fratura, já que a consciência se opunha de modo radical à existência ${ }^{3}$.

Ideologia do trabalho é, consequentemente, esse amplo conjunto de representações que orientam a conduta para o esforço, à dedicação e à entrega ao processo de trabalho como tal, justificando essa orientação como necessidade natural, social, subjetiva ou mesmo histórica - isto é, a construção de um novo mundo através do trabalho, seja o mundo mercantil, "o novo mundo industrial" (Fourier) ou o mundo socialista. Essa ideologia, de conteúdos variados, conforme o espectro político (desde o conservadorismo até o marxismo), possui, contudo, uma identidade em sua forma de relacionamento com a realidade - exprime uma tensão e uma dialética que tanto corrige quanto aceita o "mundo do trabalho"4. A ideologia é um conjunto de representações autônomas que guarda uma independência frente à objetividade, mas que nela está de algum modo ligada. A ideologia do trabalho pode ser reconhecida como a contrapartida subjetiva, tanto formal quanto em termos de seus conteúdos, da forma do trabalho na sociedade burguesa - que, como "trabalho abstrato" (MARX, 1985) pode conter uma miríade de atividades concretas, secundárias do ponto de vista da lógica da acumulação e pode mesmo se manifestar como uma "abstração real", ao lado das atividades concretas. A autonomia da ideia frente à realidade é uma condição para a legitimação através dos seus conteúdos assim como torna possível a crítica.

Todavia, o nexo entre uma ideologia do trabalho emulativa e o contexto social se rompeu com a emergência da "sociedade de consumo" ou, para ficarmos numa expressão conceitual muito mais precisa, com a constituição da "indústria cultural". Theodor W. Adorno e Max Horkheimer, companheiros de Marcuse no Instituto de Pesquisas Sociais de Frankfurt, já haviam compreendido que a industrialização dos meios e da esfera cultural, desenvolvida no início do século 20, tendia a dissolver a frugalidade e a contenção contida no ethos clássico. Isto é, o alargamento da mercantilização para o âmbito das produções estéticas - elemento-chave para explicar também a sobrevida do modo de produção depois de 1929 - rompia com o ascetismo voltado ao mundo da conduta protestante e que, segundo Weber, teria se universalizado. A rica interpretação contida na Dialética do esclarecimento, aliás, ainda opunha a promiscuidade de um consumo administrado à falsidade das intenções de satisfação da própria indústria, que não realizava nunca suas promessas e, portanto, era ao mesmo tempo "pornográfica e puritana” (ADORNO; HORKHEIMER, 1986, p. 131).

Marcuse (1999, p. 18) desenvolveu isso, posteriormente, alertando que os valores correspondentes à ética do trabalho estavam em decadência: "toda a ética puritana, de cujo funcionamento o capitalismo depende, a ética puritana do trabalho parece ter desaparecido, não são mais sentidas como necessidade indispensável nem, de modo algum, como valor". Marcuse, como lhe era peculiar, tratava esse enunciado tanto de modo positivo quanto negativo, alertando de um lado para a crescente divergência em relação a uma lógica produtivista, mas, de outro - e mais enfaticamente -, vendo nisso uma face da "dessublimação repressiva", da própria satisfação administrada dos desejos e das necessidades individuais ${ }^{5}$.

Mesmo nos países do "socialismo real", antes de sua decomposição, a ideologia do trabalho já não convencia mais ninguém: "emparedados" que estavam os sujeitos às suas individualidades, descrentes em relação ao stakhanovismo, meros executantes de funções de uma máquina que ninguém levava mais a 
sério ou seduzidos pelas parcas benesses do mercado - no caso da vitrine do "socialismo de consumo estatal" da Alemanha Oriental -, não havia mais necessidade de desenvolver forças produtivas a fím de construir uma nação, mas somente simular a força e a capacidade produtiva de um Estado proletário que fazia vista grossa frente ao mercado negro ${ }^{6}$.

\section{Antinomia entre cultura e estrutura social}

Com a indústria cultural, uma mudança no caráter da ideologia começa a ser percebido. A forma da ideologia começa a se modificar, pois o âmbito mesmo da "produção simbólica", isto é, o amplo espectro das produções espirituais está agora organizado segundo os critérios da economia de mercado - cinema, jornais, revistas, rádio, televisão, literatura e a arte em geral caem sob o mesmo manto da objetividade do trabalho abstrato e se transformam em ramos do investimento e do lucro. A autonomia da produção espiritual se perde frente a uma condição marcada pela mercantilização generalizada: não pode ficar a forma da ideologia, e em particular a ideologia do trabalho, na cômoda posição de representar algo outro que não a efetividade e, assim, deixa de legitimar a realidade com a qual se defrontava.

Além da teoria crítica dos frankfurtianos, alguns sociólogos também enxergaram esse fenômeno de decadência da ética do trabalho, entre eles o conservador Daniel Bell. Escrevendo no início da década de 1970, Bell (1977) fazia uso metodológico do próprio Weber - a quem Marcuse criticara - e argumentava que a cultura havia se tornado "antinômica" em relação às esferas da política e da economia. Levando à frente a ideia de "autonomia das esferas de valores", alertava em $A$ sociedade pós-industrial para uma "disjunção entre a cultura e a estrutura social", pois valores hedonistas e niilistas, na primeira, se contrapunham à tendência burocratizada de radicalizar a racionalidade funcional, na segunda ${ }^{7}$. Bell escrevia à sombra da contracultura e das revoltas estudantis da década anterior e frisava tanto esse processo que o considerava mesmo o substituto do modelo clássico de conflito social baseado nas classes, um dos sintomas da emergência da "sociedade pós-industrial".

A intenção de Bell, tendo a teoria marxista como alvo principal, era anunciar uma nova configuração social em que as relações mantidas no âmbito do trabalho já não eram determinantes para a identidade social, em que os diversos grupos sociais estavam passando por uma profunda transformação e em que o "trabalho" já não era mais o mesmo, dado o crescimento dos quadros intelectuais assalariados num ritmo muito maior ao do conjunto da força de trabalho. Uma das conclusões de Bell era taxativa: "O fato crucial é que a 'questão do trabalho' como trabalho deixou de ser central e não tem um peso sociológico e cultural suficiente para polarizar todas as outras questões em torno desse eixo" (BELL, 1977, p. 189) ${ }^{8}$.

O sociólogo Claus Offe, não obstante, foi o pesquisador que defendeu de modo mais veemente essa tese de decadência dos valores que permeavam a ideologia do trabalho. Através da análise de uma série de pesquisas empíricas, ele pôde constatar o evidente desapego de jovens, estudantes e dos próprios trabalhadores às relações e aos símbolos do ambiente de trabalho. Teorizando sobre essa situação subjetiva, a cujos efeitos se somavam também os problemas objetivos de crescimento sem emprego (jobless growth), da automação e da possibilidade aberta (na década de 1970) de redução da jornada de trabalho, Offe (1989) lançou a famosa tese de "perda da centralidade do trabalho", provocando ojeriza principalmente à esquerda, que via nisso a deslegitimação de sua principal fundamentação teórica e política.

Embora a sua avaliação de uma mudança profunda na sociedade capitalista seja de difícil contestação, mesmo que a sua tese de "crise da sociedade do trabalho" exprima com grande precisão os problemas sociais enfrentados pela acumulação capitalista, o problema dessa "perda de centralidade do trabalho" é a sua brevidade histórica. Ainda que consciente do problema do desemprego crescente, a formulação de Offe ficou presa a uma situação histórica em que o Estado do bem-estar social ainda não havia sofrido os ataques mais violentos (embora o próprio sociólogo "herdeiro de Frankfurt" estivesse alertando para a "crise estrutural do Estado") e por isso a automação podia implicar ainda em redução de jornada de trabalho, sem ou com redução salarial - uma das constatações de Offe junto aos operários e funcionários de escritório era a de que a maioria concordava em perder parte do salário em troca de mais tempo disponível junto da família, para viajar ou aprender e realizar atividades que realmente os "enriquecessem".

A tese da "perda de centralidade do trabalho" padeceu, sobretudo, por ter sido formulada num momento de transição raramente identificado: a já longa decadência do ethos protestante e sua substituição por um consumismo desenfreado agora se via às voltas com o problema do desemprego em massa. A ideologia do trabalho ganhava uma nova roupagem no momento em que Offe insistia em seu sepultamento. A "perda de centralidade do trabalho" ficou restrita a um pequeno limiar histórico em que a crise não era sentida de modo mais trágico ou os seus primeiros efeitos ainda podiam ser compensados pelo providencial Welfare State (o desemprego crescente, por exemplo, ainda podia ser mantido pelo seguro-desemprego ou adiantando aposentadorias). A "sociedade do tempo livre", assim, foi um breve horizonte ainda crível, que seduziu uma série de teóricos 
e serviu mesmo de motivo de reflexão nos sindicatos e no seio do movimento operário.

Entretanto, é necessário precisar de que modo nesse segundo momento da ideologia do trabalho a sua forma se modifica: se a ideologia não é mais um campo representacional autônomo frente à realidade - que contém tanto o momento de elogio quanto de tensão -, o que ocorre aos "ideais" com a queda do ethos comedido do esforço e da renúncia?

A difícil compreensão desse momento de transição na ideologia do trabalho se deve ao fato de que a tese weberiana tornou-se falsa na sua pretensão de confiar na autonomia da esfera de valor, embora seja verdadeira no que se refere aos conteúdos, ou melhor, permanece correta com a mudança no conteúdo dos valores espirituais: é como se a estrutura na qual se realiza a produção ideológica tivesse sido incorporada à estrutura social - indústria cultural nada mais é do que industrialização da cultura, sua integração à economia. Mas essa integração ocorre num momento de mudança de conteúdo - os elementos conceituais legitimadores que ornamentavam uma realidade vil são agora alheios à essa estrutura. A esfera cultural, por assim dizer, foi incorporada e colonizada pela economia industrial, mas a sua anexação se deu ao preço da indiferença de seus conteúdos frente a essa economia: a indústria cultural é apologética de si mesma, de seus valores consumistas, hedonistas e perdulários, com o que substitui a parcimônia de uma ética envelhecida da poupança e da ascese.

Há uma inversão na relação entre a forma da ideologia e seus conteúdos frente à estrutura social como tal: cindida e legitimadora no período clássico, ela se torna agora, com a "sociedade afluente" da indústria cultural, integrada e indiferente. É importante, quanto a isso, que Bell tenha tratado da "antinomia" entre cultura e estrutura social: a disjunção entre as duas esferas ocorre apenas no plano dos conteúdos, pois, no que concerne à forma, elas se integraram. A sua pesquisa empírica o comprova:

$\mathrm{Na}$ estrutura social da sociedade erudita existem, por exemplo, uma profunda e sempre crescente cisão entre os intelectuais técnicos, empenhados numa racionalidade funcional e nas modalidades tecnocráticas de operação, e os literatos, que se vão tornando cada vez mais apocalípticos, hedonistas e niilistas (BELL, 1977, p. 243).

Ora, a natureza da antinomia só se refere aos conteúdos, pois na "sociedade erudita", atravessada pela educação em massa, pelo poder intelectual e pela emergência da tecnocracia, os literatos niilistas e hedonistas estão tão "conformes" ao consumo quanto exige a acumulação ampliada. Assim, o conceito de "serviços" em Bell, que envolve um grande conjunto de atividades, só confirma a complementação do consumo em massa dos bens pelo consumo em massa dos serviços, mesmo àqueles que vão contra a lógica tradicional do esforço e da labuta ${ }^{9}$. Desde a polêmica de Hegel com Kant sabe-se que antinomia não é necessariamente "contradição".

\section{Crise do trabalho e ideologia reformulada}

A crise fiscal do Estado cujos efeitos na conservadora década de 1980 deu início ao desmantelamento do Estado do bem-estar social. As taxas de desemprego que bateram em quase toda Europa na casa dos dois dígitos. A precarização crescente dos empregos. O achatamento do poder aquisitivo dos salários (que nos Estados Unidos se depreciam por quase três décadas). As privatizações em todo mundo e o ataque aos "privilégios" dos servidores públicos. A desregulamentação econômica mundial que baixou as "barreiras de entrada" aos produtos das "plataformas de exportação" do Terceiro Mundo e construiu um mercado mundial de força de trabalho em que os altos salários do Primeiro Mundo viram-se ameaçados diretamente pelas remunerações miseráveis da periferia. Em suma, todo o conjunto de desgraças do "colapso da modernização" (KURZ, 1993) deu um fim rápido à utopia do tempo livre. A tese da "perda de centralidade do trabalho" não podia também permanecer de pé.

$\mathrm{O}$ aguilhão do desemprego em massa e a redução da seguridade forçaram o retorno ao trabalho; a concorrência acirrada no mercado rebaixou o preço da força de trabalho; a instabilidade no emprego justificou reduções em benefícios ou salários; o fenômeno secular de redução da jornada começou a se inverter; a oferta massiva de força de trabalho barata reativou condições aviltantes (minas ucranianas que remontam a Germinal voltaram a funcionar administradas pelos próprios trabalhadores); os cursos de "reciclagem" se popularizaram frente a uma dinâmica implacável de modificação nos processos de produção; e, por fim, a reengenharia empresarial e o discurso do "associado da empresa", do "colaborador" ou do "livre-empreendedor" transformaram a utopia do tempo livre num inferno - a jornada, flexibilizada, passou a avançar para a vida privada e o trabalho se integrou à vida. Como ressaltou Gorz (2005, p. 24-25), antigo proponente da "sociedade do tempo livre",

Com o autoempreendimento, a transformação em trabalho (mise em travail) e a redução a um valor (mise em valeur), de toda a vida e de toda pessoa, podem finalmente ser realizadas. A vida se torna 'o capital mais precioso'. A fronteira entre o que se passa fora do trabalho e o que ocorre na esfera do trabalho apaga-se, não porque as atividades do trabalho e as 
de fora mobilizem as mesmas competências, mas porque o tempo da vida se reduz inteiramente sob a influência do cálculo econômico e do valor.

$\mathrm{Na}$ arena política, o "consenso neoliberal das elites" (KURZ, 1993) tornou-se supra-partidário: o lema originalmente social-democrata de "trabalho, trabalho, trabalho" virou jingle de campanha política em todo espectro político. O trabalho, então, "subjetivamente" retornou ao centro de sociabilidade, onde, aliás, "objetivamente" nunca deixou de estar. Embora certamente em crise, o trabalho não foi "descentrado", pelo contrário, passou a se afirmar de modo ainda mais violento. $\mathrm{O}$ próprio Gorz (2004, p. 65) reconheceu o fracasso do projeto de sociedade baseado no tempo livre e admitiu a manutenção da "centralidade do trabalho":

Pois,o poder sem entraves que o capital impôs ao trabalho, à sociedade e à vida de todos, cabe precisamente no fato de que o 'trabalho' [...] conserva a centralidade na vida e na consciência de cada um, embora seja massivamente eliminado, economizado e abolido em todos os níveis da produção, na escala da sociedade inteira e do mundo inteiro.

Deste modo, o tempo livre, desenvolvido pela reestruturação produtiva, reorganização econômica e pelas descobertas da microeletrônica e robótica, tornou-se uma libertação totalmente negativa, pois ao invés de permitir o desfrute do ócio passou a representar a expulsão do trabalho. Nada mais natural, portanto, que uma situação de desemprego em massa e de precarização crescente dos postos de trabalho reativasse a antiga ideologia: novamente o trabalho voltou ao centro da vida social, como o nexo cultural básico e uma "virtude". O espírito hedonista que parecia soterrar o apreço ao sacrifício foi posto em xeque.

Contudo, a reativação do ethos do trabalho a partir da década de 1980 apresentou nuances. A sua ideologia passou por uma nova mudança de forma e de conteúdo, expressão de uma alteração na sua própria relação com a realidade crítica do "mundo do trabalho".

O retorno dos discursos de valorização do trabalho está longe de corresponder a uma retomada sem modificações do seu ethos, do ascetismo e da entrega calvinista ou socialista. Atualmente, a ideologia do trabalho não pode ser mais tratada como "falsa consciência", porque de modo algum ela se contrapõe à miserável empiria do trabalho concreto. Pelo contrário: as condições precárias, as longas jornadas, a instabilidade do emprego e o aviltamento não são mais bordados por ideais celestiais de enobrecimento, de enriquecimento objetivo e subjetivo ou de autoformação. A ideologia do trabalho, hoje, consiste na pura e simples afirmação das condições dadas: não se trata de escamotear o conteúdo desumano do trabalho, mas demonstrar que fora dele não há possibilidade sequer de vida. Trata-se de não mais enternecer o trabalho, mas de admiti-lo como tal, frente às condições objetivas de exclusão crescente: "qualquer trabalho é melhor que nenhum", teria dito Bill Clinton.

Aqui, o conteúdo e as condições em que se realizam o trabalho perdem qualquer importância e, com isso, são destituídos os floreios em torno da sua processualidade formativa. A legitimação da ideologia em sua forma clássica foi substituída pela mera afirmação. $\mathrm{O}$ empenho vocacional na atividade não encontra mais apelo algum, assim como o seu traço de predestinação (a graça transcendental não acessada). O trabalho não é mais virtude alguma, mas mera necessidade de reprodução - e toda a sua ideologia contemporânea o afirma. Não se trata mais de apelar para um "salário justo para um trabalho digno", mas sim de admitir, na falta de qualquer alternativa, que vale "um salário mínimo para um trabalho qualquer". O trabalho não perdeu a centralidade na vida social em que: quem o tem se entrega completamente para não perdê-lo; e quem não o tem faz de tudo para obtê-lo ou mesmo substituí-lo (através do crime, isto é, do trabalho "ilícito"). A centralidade tornouse puramente negativa, sem necessidade de fundamentação ou legitimação - basta que seja aceito, e isso se faz com a objetividade crua da selvageria mercantil ${ }^{10}$.

A ideologia do trabalho deimicroeletrônica e robótica, tornou-se uma libertação totalmente negativa, pois ao invés de permitir o desfrute do ócio passou a representar a expulsão do trabalho. xou de se opor de se complementar a uma realidade social que a desmascarava, não é mais um ideal falso frente a uma existência verdadeira. A ideologia do trabalho é a aceitação subjetiva da condição objetiva. A objetividade, por assim dizer, determina coativamente a representação e não lhe permite respirar. Agora, tanto na forma quanto no seu conteúdo o espiritual se integrou ao material: não há mais contradição, antinomia ou mera opo- 
sição - "a ideologia e a realidade correm uma para a outra; porque a realidade dada, na falta de outra ideologia mais convincente, converte-se em ideologia de si mesma" (ADORNO; HORKHEIMER, 1969, p. 205).

A idealização não passa de uma direta derivação do que está dado. A própria "representação" é agora "expressão" da existência, o que significa que mesmo esta sua direta verdade - ao afirmar as condições indignas em que devemos nos empregar - é uma falsidade como "forma". É uma falsidade não pelo "que" expressa, mas "como" expressa: uma ideia totalmente idêntica à realidade não é mais ideia. É como se a cortina de fumaça que a ideologia possuía na sua forma clássica tivesse se esvaecido, mas o que restou não é um conhecimento claro e transparente "sobre" o mundo, é um conhecimento "no" mundo e, portanto, irreflexivo ${ }^{11}$.

A ideia deixou de se apresentar como uma legitimação e ao mesmo tempo uma correção frente ao mundo danificado - trata-se de sua acolhida e ponto. O ideal não é mais uma cortina que encobre a objetividade crua do mundo, ele é muito mais uma transparente capa que o protege e o confirma, "a ideologia já não é mais um envoltório, mas a própria imagem ameaçadora do mundo" (ADORNO; HORKHEIMER, 1969 , p. 205). Nesse sentido, a própria ideologia do trabalho deixou de ser "ideologia": ela é uma pura admissão do existente, uma aprovação que não precisa de fundamentação, pois o seu fundo é sua própria existência. A unidimensionalidade da "sociedade do trabalho" em crise se manifesta por essa clara identificação entre consciência e existência que, por isso, impede qualquer movimento crítico-negativo: "A objetividade nas relações humanas, que acaba com toda ornamentação ideológica entre os homens, tornou-se ela própria uma ideologia para tratar os homens como coisas" (ADORNO, 1993, p. 35). Num mundo em que a representação foi achatada pelo peso da efetividade social, a "forma" da ideologia modificou-se junto com o seu "conteúdo": não apenas a realidade é agora contida na representação, mas a própria representação é um elogio manifesto à realidade "dada". A ideologia do trabalho persiste depois de uma série de transformações substanciais no nexo entre ideologia e realidade: a consciência não é mais uma câmara escura que inverte os seus objetos, agora os objetos aparecem de modo nu e cru na consciência e, por isso, a reificam.

\section{Referências}

ADORNO, T. W. Mínima moralia. Tradução de Gabriel Cohn. São Paulo: Ática, 1993.

ADORNO, T. W.; HORKHEIMER, M. La sociedad. Lecciones de sociología. Buenos Aires: Editorial Proteo, 1969.
. Dialética do esclarecimento (fragmentos filosó-

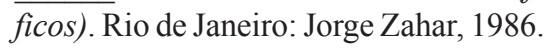

BARTA, P. Trabalho informal, uma alternativa à crise? Wall Street Journal, 16 de março de 2009. Disponível em:< http:/ /online.wsj.com/public/article/SB123715821999035023. html\#mod=2_1557>. Acesso em: 20 abr. 2009.

BELL, D. O advento da sociedade pós-industrial - uma tentativa de previsão social. São Paulo: Cultrix, 1977.

ELIAS, N. O processo civilizador. Rio de Janeiro: Jorge Zahar, 1993. (v. II).

FERNANDES, D. Empresa propõe Brasil como opção a demissões na França. BBC Brasil, 04 de abril de 2008. Disponível em: <http://www.bbc.co.uk/portuguese/ reporterbbc/story/2008/04/080404_francafuncionarios daniela_pu.shtml>.Acesso em: 5 abr. 2008.

GORZ, A. Misérias do presente, riqueza do possível. Rio de Janeiro: Annablume, 2004.

. O imaterial: conhecimento, valor e capital. Rio de Janeiro: Annablume, 2005.

JAPPE, A. As aventuras da mercadoria: para uma nova crítica do valor. Lisboa: Antígona, 2006.

KURZ, R. O colapso da modernização. Da derrocada do socialismo de caserna à crise da economia mundial. Rio de Janeiro: Paz e Terra, 1993.

LOUREIRO, I. A grande recusa hoje. Petrópolis: Vozes, 1999.

MARCUSE, H. Ideologia da sociedade industrial. Rio de Janeiro: Zahar, 1967.

. Eros e civilização. Rio de Janeiro: Zahar, 1968.

. Industrialização e capitalismo na obra de Max Weber. Cultura e sociedade, Rio de Janeiro: Paz e Terra, p. 113-136, 1998. (v. II)

. Entrevista. In: LOUREIRO, I. A grande recusa hoje. Petrópolis: Vozes, 1999. p. 11-25.

MARX, K. O Capital - crítica da economia política: O processo de produção do capital. São Paulo: Nova Cultural, 1985. (livro 1 tomo 1).

. En torno de la crítica de la filosofia del Derecho de Hegel. Introducción. In: MARX, K. Escritos de juventud. Cidade do México: Fondo de Cultura Econômica, 1987. p. 491-502. 
OFFE, C. Trabalho e sociedade. Problemas para o futuro da 'sociedade do trabalho' - A crise. Rio de Janeiro: Tempo Brasileiro, 1989. (v. I).

WEBER, M. A ética protestante e o espírito do capitalismo. São Paulo: Martin Claret, 2001.

\section{Notas}

1 De extrema atualidade, Marcuse (1998, p. 118) escreve sobre a "obsolescência planejada" como uma marca de um modo de vida burguês que não representa mais o "desenvolvimento das forças produtivas", pois do que se trata é "muito mais o estigma da destruição produtiva nos termos da administração total".

2 “A administração científica das necessidades instintivas converteu-se, desde há muito, em fator vital na reprodução do sistema: a mercadoria que tem de ser comprada e usada traduz-se em objetos da libido"(MARCUSE, 1968, p. 14).

3 Na bela expressão clássica de Marx, referindo-se à religião como ideologia - o que pode ser estendido sem dúvida ao caráter religioso da ideologia do trabalho, já que os debates na esquerda hegeliana giravam em torno da relação entre filosofia e religião -, "'a miséria da religião é, de um lado, a expressão da miséria real e, de outro, o protesto contra ela.A religião é o soluço da criatura oprimida, o coração de um mundo sem coração, o espírito de uma situação carente de espírito"(MARX, 1987,p.491).

4 É verdade que a posição de Marx é extremamente ambígua e não pode ser reduzida ao positivismo desta ideologia, isto é, a mera aceitação do "dado", mesmo que este contrarie os ideais: é que em Marx podemos encontrar tanto momentos de um elogio do esforço que remonta ao ethos protestante (por exemplo, sua recusa de aceitar o "trabalho atrativo" de Fourier) como momentos de uma crítica radical, não apenas da ideologia do trabalho, mas da forma do trabalho na sociedade capitalista: "É um dos mais graves equívocos falar de trabalho livre, humano, social, de trabalho sem propriedade privada. O 'trabalho' é, pela sua própria essência, a atividade não livre, inumana, não social, condicionada pela propriedade privada e que por seu turno a cria. A superação da propriedade privada só se tornará realidade se for concebida como superação do "trabalho"" (MARX apud JAPPE, 2006, p. 113).

5 É extremamente significativo que em Ideologia da sociedade industrial, obra polêmica, Marcuse (1967, p. 31) tenha chegado ao ponto de argumentar que mesmo o conceito clássico de "alienação" teria caducado, pois a extensão do mundo subjetivo no mundo das mercadorias faria os indivíduos se identificarem "com a existência que lhes é imposta.”. Essa afirmação não deixa de encadear uma série de reflexões, mas apenas para quem percebe a diferença conceitual entre "alienação" e "fetichismo" pode explorá-la de modo rico e sem perseguição ortodoxa.

6 Uma piada popular na URSS da década de 1980 dá conta dessa mudança de ethos nas últimas décadas do regime em que o stakhanovismo caducou. Stálin, Kruschev e Brejnev viajavam num mesmo trem que, a certa altura do caminho, parou porque faltavam trilhos à frente. Stálin tomou o comando da situação, mandou fuzilar metade dos funcionários da ferrovia e condenou a outra metade por traição, forçando camponeses locais a trabalharem assentando novos trilhos. $\mathrm{O}$ trem seguiu viagem, mas não demorou muito e parou novamente. Coube a Kruschev resolver o problema dessa vez: reabilitou os funcionários condenados por Stálin, que trabalharam retirando os trilhos anteriores e os colocando à frente do trem, para seguir viagem. Não demorou e o trem parou mais uma vez, mas, como agora a responsabilidade cabia a Brejnev, este mandou que os funcionários fechassem as cortinas dos vagões e que todos balançassem os corpos - o trem continuava parado, mas pelo menos havia a sensação de que estava em movimento.

7 A estrutura social, na concepção teórica de Bell (1977, p. 25 27), "abrange a economia, a tecnologia e o sistema ocupacional."

8 Embora de importância fundamental para discutir a "sociedade pós-industrial" e todas as suas implicações, o conceito de trabalho não passa em nenhum momento por uma reflexão, resultando numa mera associação com esforço físico.

9 "Desta maneira, começa a desenvolver-se um terceiro setor, o dos serviços pessoais: restaurantes, hotéis, postos de serviços para automóveis, viagens, diversões, esportes, à medida que os horizontes das pessoas se vão ampliando e surgindo novas necessidades e preferências"(BELL, 1977,p. 148).

10 Veja o caso dessa situação: uma multinacional do setor têxtil anunciou um plano de demissão em sua filial francesa e propôs cinicamente aos futuros desempregados que retomassem suas mesmas funções na cidade mineira de Alfenas, onde possuía também uma fábrica e onde seriam abertas novas vagas. Detalhe: os cargos seriam retomados com um salário equivalente a um terço do anterior (FERNANDES,2008).

11 Em recente artigo publicado no Wall Street Journal, por exemplo, discute-se o papel do trabalho informal na recente crise econômica desencadeada pelo subprime: o resultado a que chega o autor, tão absurdo e ao mesmo tempo tão verdadeiro, "cínico", é que o setor informal "se tornou uma rede de segurança crucial diante da crise" (BARTA, 2009). O achatamento do horizonte reflexivo é tal que basta simplesmente a confirmação do existente. 


\section{Maurilio Lima Botelho}

mauralio@bol.com.br

Doutorado em Desenvolvimento, Agricultura e Sociedade pelo Programa de Pós-Graduação de Ciências Sociais em Desenvolvimento, Agricultura e Sociedade da Universidade Federal Rural do Rio de Janeiro (UFRRJ)

Professor substituto do Departamento de Letras e Ciências Sociais, do Instituto de Ciências Humanas e Sociais (ICHS) da UFRRJ

\section{UFRRJ}

Departamento de Letras e Ciências Sociais

BR 465, km 7

Seropédica - Rio de Janeiro - Brasil

CEP: 23890-000 